\title{
A Seguro... Sobre incertidumbres, objetividad y cientificismo
} Nothing is certain... A comment on uncertainty, objectivity and scientism

"A seguro se lo llevaron preso", dice el refrán popular. El origen de la frase se remonta a que, en España, existía un castillo, el castillo de Segura de la Sierra, que servía de prisión. Era una cárcel para los delincuentes comunes, quienes tenían muy pocas probabilidades de sobrevivir en ese lugar, pero también era un lugar de detención para los personajes de cierta alcurnia, que no permanecían en ese lugar por demasiado tiempo. No importaba la condición social de las personas; cualquiera podía ser encarcelado en ese lugar si cometía algún hecho delictivo, por lo que el dicho original sería: "A Segura -haciendo referencia a la prisión-, lo llevaron preso". En español, existe el adjetivo "seguro/a", por lo que se da un juego de palabras entre el nombre propio "Segura" y el adjetivo "seguro/a". En definitiva, quiere decir que no importa cuál sea la condición social de las personas, todas pueden ser encarceladas si sus acciones no son las correctas de acuerdo con la ley. En nuestro país, se utiliza la frase para dar a entender que nadie está exento (seguro) de que le pase algo, bueno o malo. ${ }^{1}$

La medicina habita su propia prisión de Segura, construida con su pretensión de objetividad y su falsa ilusión de certeza amalgamada por su cientificismo. Se ha quedado estancada en el paradigma del positivismo y del positivismo lógico o concepción heredada $(\mathrm{CH})$, fundada por el Círculo de Viena en los años veinte del siglo pasado. ${ }^{2}$ Los supuestos de esta escuela de pensamiento son los siguientes:

\section{Figura 1: Castillo de Segura de la Sierra, Andalucía}

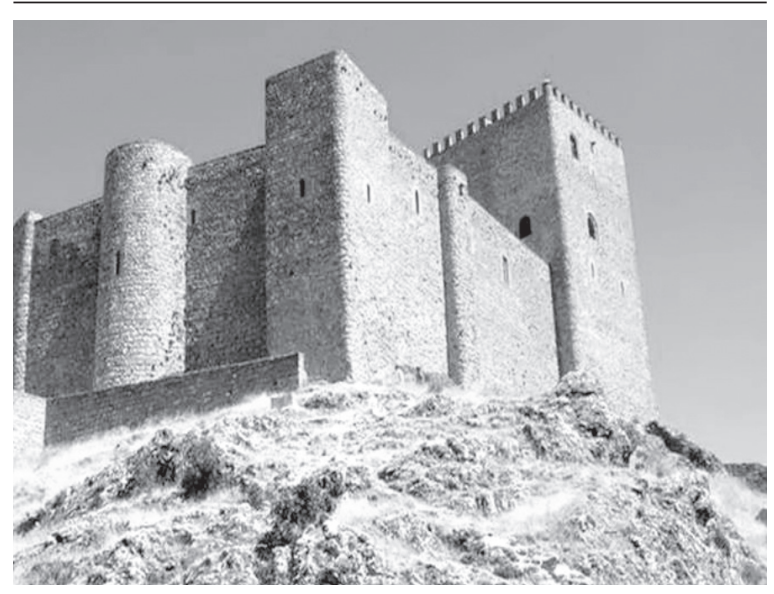

- Empirismo: El positivismo postula el conocimiento positivo (empírico, objetivo y con formalización de los fenómenos) como único método valedero para acceder al conocimiento.

- Racionalización: Reduce la razón a la ciencia. El conocimiento científico aparece no solo como el exponente más elevado y acabado de la razón humana, sino que se constituye en la única racionalidad posible.

- Reduccionismo: La CH postula la unidad metodológica, mantiene la fe en lo fundamental del método científico, sostiene que el modo de acceso al conocimiento es el mismo para todo saber. Esto implica que el modelo del saber es la física.

- Rechazo a la metafísica: La CH pretende desentenderse de los problemas de la producción del saber. No se interesa por la génesis del conocimiento científico, contexto de descubrimiento, ya que este será un problema para la sociología, la historia o la psicología. Se ocupa de las cuestiones de justificación o validez de las hipótesis, contexto de justificación, a través de dos instancias: el control empírico (por medio de los sentidos) de sus enunciados de primer nivel y la validez lógica, o sea, la corrección de la estructura deductiva que vincula las hipótesis fundamentales con los enunciados empíricos. El hecho de que únicamente estas sean las instancias decisorias de la verdad o falsedad de las teorías científicas permitiría garantizar lo que, para el positivismo, es condición básica del conocimiento científico: la objetividad del saber. Así, la postura del Círculo de Viena llevó adelante una militancia antimetafísica.

Un rasgo distintivo del positivismo lógico es su carácter ampliamente reduccionista. Reduce unas ciencias a otras; reduce el conocimiento humano relevante a aquel que tiene su origen en lo empírico; pretende reducir la diversidad metodológica a la unidad, y, finalmente, realiza una estratégica e ideológica doble reducción: reduce la racionalidad a la ciencia y esta a sus aspectos puramente metodológicos (el control lógico y empírico de las teorías científicas).

Este marco teórico mostró rápidamente sus insuficiencias; las primeras críticas surgieron 
desde su propia nave insignia, la física. La segunda ley de la termodinámica ${ }^{3}$ demolió la reversibilidad de los procesos, y el principio de incertidumbre de Heisenberg ${ }^{4}$ sepultó toda pretensión de certeza absoluta. Es que la certeza está íntimamente relacionada con la entropía, es decir, el grado de desorden que tiene un sistema. La palabra "entropía" procede del griego $\mathrm{em}$, que significa "sobre, en y cerca de", y sqopg, que significa "giro, alternativa, cambio, evolución o transformación", y es un patrón de medida. En física, esto se aplica a la segunda ley de la termodinámica, según la que los sistemas aislados tienden al desorden, es decir, las cosas tienden al caos a medida que pasa el tiempo (podemos verlo en el organismo de un ser vivo). La entropía es nula cuando la certeza es absoluta y alcanzará un máximo cuando el sistema se acerca al equilibrio. Cuando la entropía sea máxima en el universo, esto es, cuando exista un equilibrio entre todas las temperaturas y presiones, llegará la muerte térmica del universo. ${ }^{5}$ Aquí aparece el concepto clave: la certeza es la muerte; en oposición, la vida es incertidumbre, cambio, riesgo.

Nuestra sociedad se obstina, como legado de la $\mathrm{CH}$, a alcanzar la certeza y el control; esta es la sociedad del panóptico diseñado por Bentham $^{6}$ (originalmente, es un diseño de cárcel) y descrita por Foucault ${ }^{7}$ en Vigilar y Castigar. El mundo actual compele a las personas a eliminar el 99,9\% de los gérmenes y, así, se embarcan en este holocausto contra natura de la ecología y la infectología porque la legitimación social de una actividad o producto radica en su origen científico.

Al igual que muchos publicistas, muchos médicos se preocupan por que, en sus avisos comerciales o textos científicos, aparezcan las palabras mágicas "está científicamente comprobado". Sin embargo, la epistemología, originada en la misma $\mathrm{CH}$, nos enseña que no podemos afirmar la verdad de ninguna teoría científica. Todo conocimiento científico es contingente y transitorio, tal como se asume en la metodología de los trabajos científicos en el falsacionismo de Karl Popper. ${ }^{8}$ Esto afirma que, en algo que está científicamente comprobado, lo único que se comprueba es su ignorancia, por lo menos, epistemológica. Además, la medicina no es ciencia; es arte o disciplina ${ }^{9}$ y navega, indefectiblemente, en las aguas de la incertidumbre.

Como alternativa a esta mirada hegemónica, Marc Jamoulle nos propone un concepto desafiante, la prevención cuaternaria (P4). ${ }^{10,11}$ Este concepto desafía los ideales positivistas de la modernidad que sostienen que la ciencia y el progreso de la sociedad son constantes y siempre para bien. Esto nos remite a la idea de iatrogenia positiva de Michel Foucault al recordarnos que la medicina adquirió la capacidad de dañar por su correcto ejercicio y no solamente por impericia o ignorancia. ${ }^{12}$ Alejarnos de la concepción de ciencia de la modernidad nos permite separarnos de la idea de que la ciencia es algo que únicamente se ocupa del conocimiento y está divorciada de la ética y de las influencias de la política y la economía.

La P4 se inició como una respuesta a los excesos de la medicalización, la venta de enfermedades (disease mongering), la transformación de factores de riesgo en enfermedades, el sobrediagnóstico, etc. Ha comprendido que las causas profundas exceden con creces los límites de la medicina; también que el problema incluye aspectos éticos, políticos, económicos y de concepción de la ciencia y la medicina. Es por esta razón que la definición de P4 se desplazó a la función de idea fundacional, ya que el movimiento que se ha generado en torno a este concepto ha superado esta inicial definición centrada en una visión biomédica.

La P4 ha comprendido que es necesario un nuevo modelo de medicina y un nuevo pacto con la sociedad. Es un movimiento ${ }^{13}$ que busca refundar los valores éticos de la medicina para que vuelva a ser una actividad para humanos ejercida por humanos y en contacto con la vida. La P4 no pretende certidumbres: no hay un punto de llegada seguro, no hay una ruta predeterminada, no hay garantías; lo único que sabemos es que estamos construyendo utopías.

Dr. Ricardo La Valle Comisión de Prevención Cuaternaria de la Federación Argentina de Medicina Familiar y General lavayear@gmail.com

http:/ /dx.doi.org/10.5546/aap.2016.293

\section{REFERENCIAS}

1. Definiciencia popular. A Seguro se lo llevaron preso. [Acceso: 2 de diciembre de 2015] Disponible en: http:// definicienciapopular.blogspot.com.ar/2008/01/segurose-lo-llevaron-preso.html.

2. La Valle R. Crisis... ¿Qué crisis? Rev Hosp Ital B. Aires 2012;32(4):158-61.

3. Eduardo C. ¿En qué consiste la segunda ley de la termodinámica? [Acceso: 28 de febrero de 2016]. Disponible en: http:/ / termodinamica-2011.blogspot.com.ar/. 